\title{
Study on shear strength of expansive soil considered softening and slope stability analysis with FLAC ${ }^{3 D}$
}

\author{
WU Junhua', a, KUANG Yuhan², b, LUO Ming ${ }^{3, c}$ \\ 1. College of Civil Engineering and Architecture, Nanchang Hangkong University, Nanchang \\ 330063, China \\ 2. Jiangxi Vocational Technical College of Industry Trade, Nanchang, 330038, China \\ 3. School of Jinggangshan Economic and Technological Development Zone, Jian, 343100, China \\ awjh0796@163.com, b305623760@qq.com, c158700655@qq.com
}

\begin{abstract}
Keywords: expansive soil, FLAC ${ }^{3 D}$, generalized plastic shear strain, slope stability, softening. Abstract. Swell-shrinkage, crack growth and over-consolidation are the main characteristics of expansive soil, and it is an over-consolidation soil undergone drying-wetting cycles. So there may be some faults to analyze expansive soil slope stability adopting the traditional strength criterion and calculation methods. In this paper, triaxial tests were carried out to obtain the relations between the parameters of shear strength and generalized plastic shear strain firstly. The soil shear strength increases and then decreases along with the increasing of shear deformation due to soil over-consolidation, and the residual strength is achieved. The functions are applied in simulating the relations between the parameters and generalized plastic shear strain in order to analyze expansive soil slope stability. Then the Strain Hardening Softening (SHS) model in FLAC ${ }^{3 \mathrm{D}}$ was adopted to analyze the slope stability combined with strength reduction method. Results showed that the SHS model could be used to analyze the expansive soil slope stability considered soil softening. The concentrated area of plastic shear strain expanded gradually from the slope base and top to the middle of slope and was linked totally. The results were indicated that the soil characteristics of softening should be considered in analysis on expansive soil slope stability and the judgment of generalized plastic shear strain for expansive slope stability by FLAC ${ }^{3 D}$ is feasible.
\end{abstract}

\section{Introduction}

Swell-shrinking, cracks and over-consolidation are the main characteristics of expansive soil. Its damage to the projects could not be neglected. So it is necessary to study on the slope stability of expansive soil. The researches on expansive soil slope at present could be concluded in stability analysis[2] and numerical simulation[3]. The characteristics of expansive soil slope can be seen as follows: cracks develop on soil surface; the soil has the properties of shear dilation and softening; the characteristics of landslide show a progressive development[4]. Skempton[5] had studied the mechanism of strength loss under long-term loading and the choice of strength parameters in slope stability respectively. The researches on expansive soil slope could be concluded in stability analysis[6], strengthening methods[7][8], numerical simulation[9][10][11] etc. The characteristics of expansive soil slope can be seen as follows: the soil has the properties of shear dilation and softening; the characteristics of landslide show a progressive and tractive development[12]. Bjerrum[13] and Bishop[14] had studied the mechanism of strength loss under long-term loading and the choice of strength parameters in slope stability respectively. The influences on strength[15] and seepage[16] by cracks are mainly focused in analysis of slope stability considered cracks. Expansive soil undergoes drying-wetting cycles is an over-consolidation soil. At the beginning of shearing, the anti-shear capacity increases rapidly with the increasing of shearing deformation and reaches to peak. Then the anti-shear capacity reduces due to softening and reaches to residual strength finally. In the process of stability analysis, the active degree of anti-shear capacity should be considered during the process of shearing. Therefore, there may be some faults to analyze 
expansive soil slope stability adopting the traditional strength criterion and calculation methods. Specifically, the key relations between the parameters of shear strength and generalized plastic shear strain should be obtained to apply in simulation analysis. Moreover, the Strain Hardening Softening (SHS) model in FLAC ${ }^{3 \mathrm{D}}$ which could consider the factors of strain hardening/softening model well was adopted to analyze the slope stability combined with strength reduction method.

\section{Basic parameters}

\subsection{Generalized plastic shear strain}

The generalized shear strain $\varepsilon_{s}$ represented the shear deformation under complex stress condition is adopted generally[17]. It is shown as follows via Eq. (1).

$$
\begin{gathered}
\varepsilon_{s}=\frac{\sqrt{2}}{3} \sqrt{\left(\varepsilon_{1}-\varepsilon_{2}\right)^{2}+\left(\varepsilon_{2}-\varepsilon_{3}\right)^{2}+\left(\varepsilon_{1}-\varepsilon_{3}\right)^{2}} \\
\varepsilon_{s}=\varepsilon_{e s}+\varepsilon_{p s}=\varepsilon_{a}-\frac{\varepsilon_{v}}{3}
\end{gathered}
$$

where $\varepsilon_{e s}$ is elastic strain; $\varepsilon_{p s}$ is plastic strain. $\varepsilon_{1}, \varepsilon_{2}, \varepsilon_{3}$ are principal strain. The $\varepsilon_{s}$ can be simplified as Eq. (2) according to the axis symmetric state of triaxial CD tests. The total strain can be obtained by triaxial CD tests directly. So the plastic strain $\varepsilon_{p s}$ is obtained naturally.

\subsection{Exertion of shear strength}

The shear capacity of over-consolidated soil increases to peak value firstly with the increasing of shear deformation. Then the shear capacity decreases quickly and to residual strength finally due to softening. Therefore, the exertion of shear strength of over-consolidated soil should be considered during the process of shearing in slope stability analysis. In other words, the shear strength changes during the process of shearing and it is related to the shear deformation. Accordingly, the exertion of shear strength $c_{e x}$ and $\varphi_{e x}$ are obtained from the principal stress difference of different confining stress at the same axis strain by CD tests.

\section{Constitutive models}

The strain-hardening/softening (SHS) model allows representation of nonlinear material softening and hardening behavior based on prescribed variations of the Mohr-Coulomb (MC) model properties (cohesion, friction etc.) as functions of the deviatoric plastic strain. The difference lies in the possibility that the cohesion, friction and tensile strength may harden or soften after the onset of plastic yield. In SHS model, the cohesion and friction can be defined as piecewise-linear functions of a hardening parameter measuring the plastic shear strain. A piecewise-linear softening law for the tensile strength can also be prescribed in terms of another hardening parameter measuring the plastic tensile strain. The code measures the total plastic shear and tensile strains by incrementing the hardening parameters at each time step, and causes the model properties to conform to the user-defined functions.

\section{Triaxial CD tests}

The triaxial CD tests were carried out and the relationship between the exertion of shear strength and generalized plastic shear strain are shown in Fig. 4. It can be seen that the cohesion exertion increases to the peak value $(24.7 \mathrm{kPa})$ with the increasing of shear deformation firstly. Now the generalized plastic shear strain is about $8 \%$. Then the cohesion exertion decreases quickly and to residual strength $(11.2 \mathrm{kPa})$ finally due to softening. In contrast, the exertion of internal friction angle increases quickly at the beginning and reach to $9^{\circ}$ when the generalized plastic shear strain is about $5 \%$. After that, the exertion of internal friction angle continues to increase and the internal friction angle is about $10.2^{\circ}$ finally. 


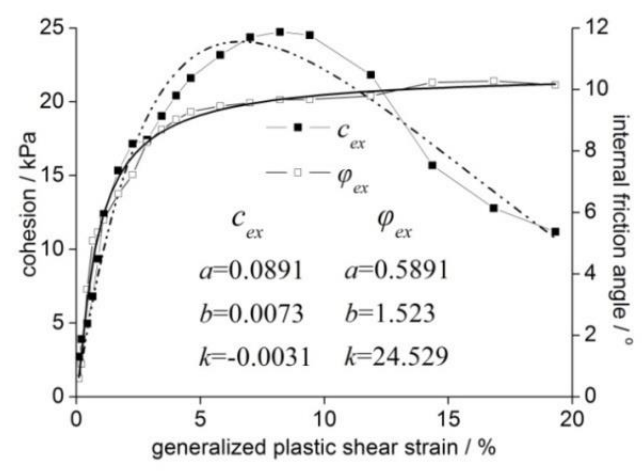

Fig. 4 the exertion of shear strength- plastic shear strain relationship

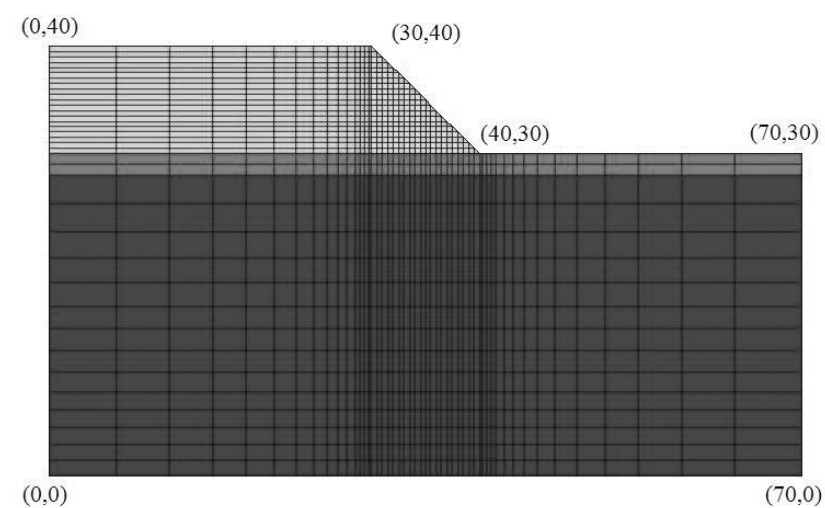

Fig. 5 The Finite Difference Mesh

A softening function[7] seen in Eq. (4) is used to fit the relationship between the exertion of shear strength and generalized plastic shear strain here. The fitting results are still shown in Fig. 4. It can be seen that Eq. (4) could be represented the relationship between the exertion of shear strength and generalized plastic shear strain reasonably. Moreover, it can be applied in simulation and theoretical analysis in slope stability of expansive soil.

$$
c_{e x}, \varphi_{e x}=\frac{\varepsilon_{p s}\left(a+k \varepsilon_{p s}\right)}{\left(a+b \varepsilon_{p s}\right)^{2}}
$$

where $c_{e x}$ and $\varphi_{e x}$ are the exertions of shear strength; $\varepsilon_{p s}$ is generalized plastic shear strain; $a, b, k$ are unknown constants, and they are listed in Fig. 4.

\section{Slope stability by FLAC ${ }^{3 D}$}

The slope stability analyses have been conducted by MC model and SHS model respectively combined with strength reduction method. The calculating model is shown in Fig. 5. The $\mathrm{x}$-displacement at $x=0 \mathrm{~m}$ and $x=70 \mathrm{~m}$ are fixed. The $\mathrm{x}$-displacement and $\mathrm{z}$-displacement at $z=0 \mathrm{~m}$ are fixed meanwhile. Here, the soil parameters (e.g., cohesion, friction angle etc.) are the brittle functions of hardening parameters and shown in Table 1.

Table 1 Parameters of Soil in FLAC ${ }^{3 \mathrm{D}}$

\begin{tabular}{c|c|c|c|c|c|c}
\hline \multicolumn{2}{c|}{$\begin{array}{c}\text { Strength } \\
\text { parameters }\end{array}$} & $c$ & $\varphi$ & $E$ & $\mu$ & $\gamma$ \\
\cline { 2 - 7 } & $/ \mathrm{kPa}$ & $/^{\circ}$ & $/ \mathrm{kPa}$ & $/$ & $/ \mathrm{kN} \cdot \mathrm{m}^{-3}$ \\
\hline \multirow{2}{*}{ Soil } & peak & 24.7 & 10.2 & 6000 & 0.44 & 14.6 \\
\cline { 2 - 7 } & residual & 11.2 & 9 & 6000 & 0.40 & 14.6 \\
\hline
\end{tabular}

The results of the distribution and variation graph of plastic shear strain are shown in Fig. 6 . The concentrated area of plastic shear strain appeared on slope base at 1000 time step (Fig. 6-(1)). The concentrated area of plastic shear strain also appeared from base to top at 1500 time step in less time (Fig. 6-(2)). The concentrated area of plastic shear strain expanded through the entire slope at about 3000 time step (Fig. 6-(3)). After that, the concentrated area of plastic shear strain was linked totally and an obvious shear zone was formed (Fig. 6-(4)). The plastic shear strain increases continually and the areas expand from the slope surface to the inner parts. The simulation results reflected the forming process of gradual landslide clearly. 


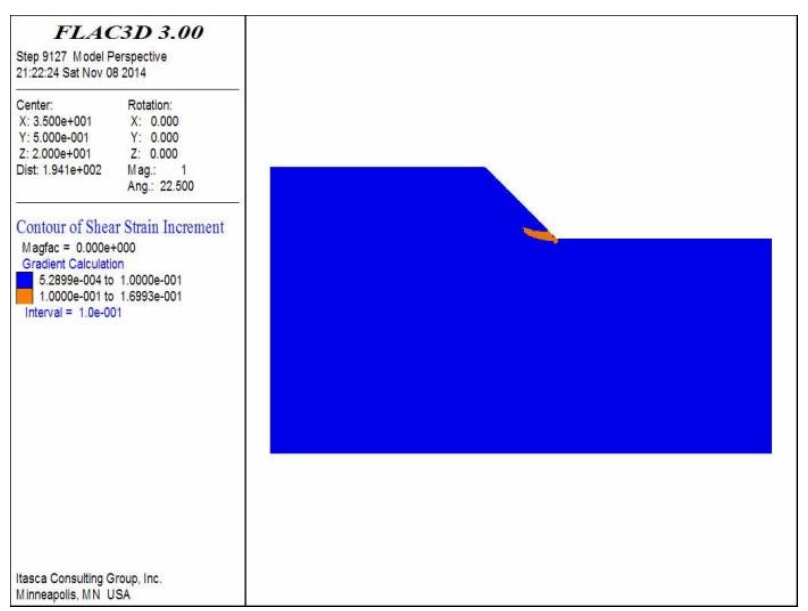

(1) 1000 time step

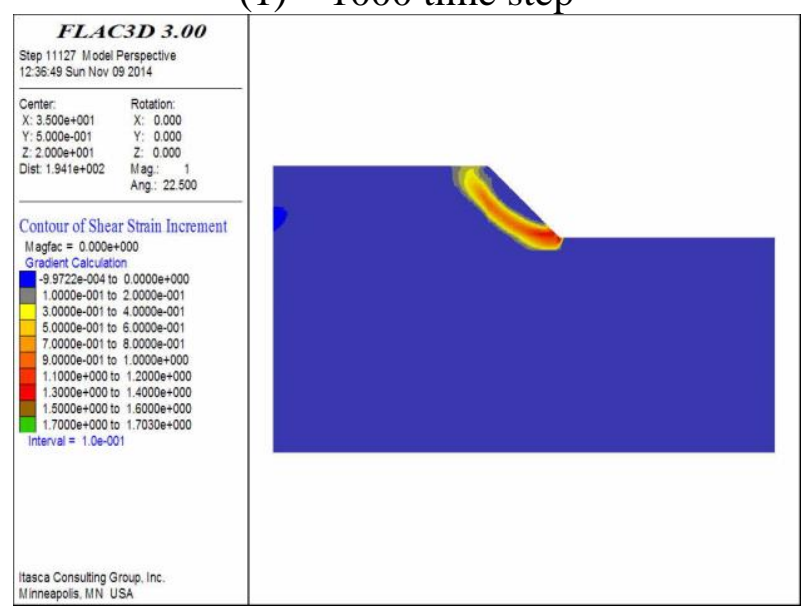

(3) 3000 time step

Fig. 6 Distribution and Variation Graph of Plastic Shear Strain

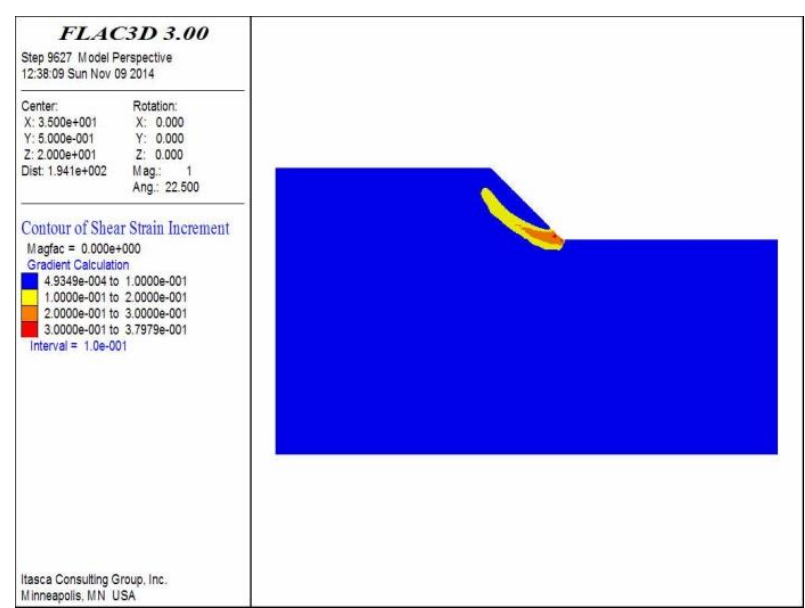

(2) 1500 time step

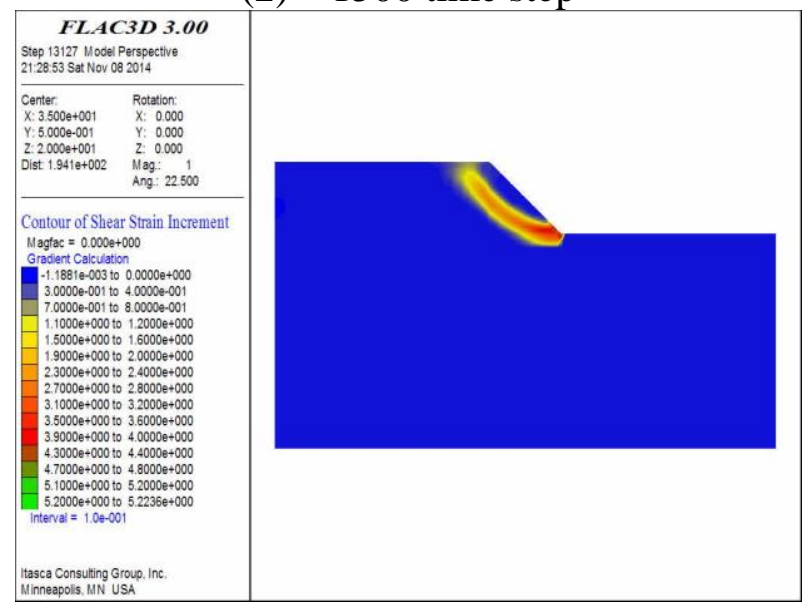

(4) 5000 time step

\section{Conclusions}

The stress-strain relations of over-consolidated expansive soil are obtained by triaxial CD tests. The cohesion exertion increases to the peak value with the increasing of shear deformation firstly. Then the cohesion exertion decreases quickly and to residual strength finally due to softening. In contrast, the exertion of internal friction angle increases quickly firstly. The exertion of internal friction angle continues to increase. The results show that the shear strength of over-consolidated soil is applied gradually while not reach to the peak value at the beginning under shearing. The cohesion and internal friction angle are provided for shearing capacity before shearing failure; while the internal friction angle is provided for shearing capacity mainly after shearing failure. A softening function is used to establish the exertion of shear strength-generalized plastic shear strain relationship reasonably. The SHS model in FLAC $^{3 \mathrm{D}}$ can be used to analyze the slope stability considered soil softening. The characteristic of expansive soil landslide can be simulated well. Plastic shear strain is adopted to represent the slope deformation at different time. The concentrated area of plastic shear strain appeared on slope base at the beginning and also appeared on slope top afterwards. The concentrated area of plastic shear strain expanded gradually from the slope base and top to the middle of slope and was linked totally in less time. The plastic shear strain increases continually and the areas expand from the slope surface to the inner parts. The simulation results reflected the forming process of gradual landslide clearly.

\section{Acknowledgements}

This work was financially supported by the National Natural Science Foundation of China 
(51408291).

\section{References}

[1] Li S. L.. Studies on the Engineering Geology of Expansive Soil in China. Jiangsu Science and Technology Publishing House, 1992.

[2] Huang R.Q., QI G.Q.. The Effect of Unsaturated Soil Suction on Slope Stability. Journal of Engineering Geology, Vol. 10, no. 4, pp. 343-348, 2002.

[3] Wu J. H., Yuan J. P., Lu T. H.. Stability Analysis of Unsaturated Expansive Soil Slope. Rock and Soil Mechanics, Vol. 29, no. S, pp. 363-367, 2008.

[4] Shen Z. J.. Theoretical Soil Mechanics. Beijing: China WaterPower Press, 2000.

[5] Skempton A. W.. Long-term stability of clay slopes. Geotechnique, Vol. 14, no. 2, pp. 77-102, 1964.

[6] Huang R.Q. and QI G.Q.. The Effect of Unsaturated Soil Suction on Slope Stability. Journal of Engineering Geology, Vol. 10, no. 4, pp. 343-348, 2002.

[7] Ying X.D.. Study on Stabilizing Effect to Expansive Soft Slope by Manual Bored Concrete Pries. Jiangsu Construction, Vol. 6, no.3, pp. 20-22, 2007.

[8] Zhang K.J.. Study on Failure Mechanism and Treatment Technology of Expansive Soil Slope in Landscape Area. Jiangsu Construction, Vol. 4, no. 5, pp. 44-47, 2006.

[9] Li Z.P. and Zhang M.. Effects of Rain Infiltration on Transient Safety of Unsaturated Soil Slope. China Civil Engineering Journal, Vol. 34, no.5, pp. 57-61, 2001.

[10] Yin K.L., Wang Y. and Tang Z.H. Mechanism and Dynamic Simulation of Landslide by Precipitation. Geological Science and Technology Information, Vol. 21, no. 1, pp. 75-78, 2002.

[11] Wu J.H., Yuan J.P. and Lu T.H. (2008). Stability Analysis of Unsaturated Expansive Soil Slope. Rock and Soil Mechanics, Vol. 29, no. S, pp. 363-367, 2008.

[12] Shen Z.J.. Theoretical Soil Mechanics. Beijing: China WaterPower Press, 2000.

[13]Bjerrum C.. Progressive failure in slopes of over consolidated plastic clay and clay shales. SMFE, ASCE, Vol. 93, no. 5, pp. 3-49, 1967.

[14]Bishop A. W.. The influences of progressive failure in the choice of the method of stability analysis. Geotechnique, Vol. 21, no. 2, pp. 168-172, 1971.

[15]Liu H.Q.. Study on analysis method and influencing factors of expansive soil slope stability. doctoral dissertation, Nanjing, HoHai University, 2008.

[16]Chen T.L., Deng G., Chen S.S. et al.. Effects of fissures on stability of unsaturated soil slope. Chinese Journal of Geotechnical Engineering, Vol. 28, no. 2, pp. 210-215, 2006.

[17] QIAN J. H.. Soil Mechanics. Beijing: Water Resources and Electric Power Press, 1994.

[18] ZHENG Y. R., SHEN Z. J., GONG X. N.. The Principles of Geotechnical Plastic Mechanics. Beijing: China Architecture and Building Press, 2002. 